\section{THU0385 SAFETY OF TOFACITINIB THERAPY IN HBSAG CARRIERS WITH ANKYLOSING SPONDYLITIS: A PROSPECTIVE STUDY}

L. Fang', Z. Lin' ${ }^{1}$, Z. Liao' ${ }^{1}$, O. Jin' ${ }^{1}$, J. Gu${ }^{1} .{ }^{1}$ The Third Affiliated Hospital of Sun Yat-sen University, Guangzhou, China

Background: Targeted synthetic DMARDs (ts-DMARDs) are becoming more available and affordable in developing countries, where the prevalence of hepatitis $B$ virus (HBV) infection is still an important public health issue. The safety of ts-DMARDs therapy in terms of the reactivation of hepatitis B virus (HBV) infection need more concern. Rare data from a prospective study focus on the use of ts-DMARDs in patients with concurrent ankylosing spondylitis (AS) and HBV infection were available by now.

Objectives: To evaluate the influence of tofacitinib on reactivation of HBV infection in HBsAg carriers with AS.

Methods: In this 52 weeks observation, HBsAg carriers with active AS (BASDAI $\geq 4$ ) despite failed treatment with at least two NSAIDs and sulfasalazine (for patients with persistent peripheral arthritis) were studied. Patients must be positive for HBsAg and have a normal liver function prior to study.

All patients received therapy with tofacitinib (5mg twice daily). Entecavir were prescribed preventively regardless of individual viral load. Pre-existing NSAIDs and sulfasalazine were allowed. Liver enzymes (AST/ALT) and HBV viral load were monitored every 4 weeks. Increased viral load and abnormal liver function were managed according to expert opinion.

Results: Eleven patients ( 9 male) were recruited. Eight patients had a baseline viral load $>2000 \mathrm{copy} / \mathrm{ml}$ (group 1), and the other 3 patients had a viral load $\leq$ $2000 \mathrm{copy} / \mathrm{ml}$ (group 2). Two patients from group 1 discontinued tofacitinib at week 12 due to ineffectiveness, and both continued taking Entecavir for another 3 months after the discontinuation of tofacitinib.

One patients (male, 26 years old) from group 1 underwent a mild increase of both ALT and AST ( 67 and $56 \mathrm{IU} / \mathrm{L}$, respectively) at week 16, but no elevated viral load (2.1 3 copies/ml, baseline 2.8e3) or a HBV YMDD mutant was found. The tofacitinib treatment continued. After prescription of polyene phosphatidyl choline, the liver enzyme of this patient decreased to normal range in 4 weeks and remained normal throughout the study.

No reactivation of hepatitis B was observed in patients from group 2.

Conclusion: Tofacitinib treatment may be a safe and effective option for $\mathrm{HBs} A g$ carriers with AS refractory to traditional treatment. Prophylaxis strategy with effective anti-viral drugs is recommended.

References:

[1] Chen YM, Huang WN, Wu YD, et al. Reactivation of hepatitis B virus infection in patients with rheumatoid arthritis receiving tofacitinib: a real-world study. Ann Rheum Dis 2018; 77:780-2.

Disclosure of Interests: None declared

DOI: 10.1136/annrheumdis-2020-eular.6445

\section{THU0386 PREDICTORS OF MAINTENANCE OF SECUKINUMAB TREATMENT IN A MULTICENTER COHORT OF 561 SPONDYLARTHRITIS}

B. Flachaire ${ }^{1,2}$, J. G. Letarouilly ${ }^{3}$, C. Labadie ${ }^{4}$, N. Cohen ${ }^{1}$, V. Pradel ${ }^{1}$, B. Fautrel ${ }^{5,6}$, G. Baudens ${ }^{7}$, P. Claudepierre ${ }^{8}$, C. Miceli Richard ${ }^{9}$, P. Dieudé ${ }^{10}$, J. H. Salmon ${ }^{11}$, J. Sellam $^{12}$, E. Houvenagel ${ }^{13}$, M. H. Guyot ${ }^{14}$, C. D. Nguyen ${ }^{15}$, X. Deprez ${ }^{16}$, I. Chary Valckenaere ${ }^{17}$, P. Lafforgue ${ }^{2}$, D. Loeuille ${ }^{17}$, C. Richez ${ }^{4}$, R. M. Flipo ${ }^{3}$, T. Pham ${ }^{1,2} .{ }^{1} \mathrm{Ap}-\mathrm{Hm}$, Marseille, France; ${ }^{2}$ Aix-Marseille University, Marseille, France; ${ }^{3}$ Chu De Lille, Lille, France; ${ }^{4}$ Hospital Center University De Bordeaux, Bordeaux, France; ${ }^{5}$ Sorbonne Université, Paris, France; ${ }^{6}$ University Hospitals Pitié Salpêtrière - Charles Foix, Paris, France; ${ }^{7}$ Private Practice, Valenciennes, France; ${ }^{8} \mathrm{Hôpital} \mathrm{Henri-Mondor} \mathrm{Ap-Hp,} \mathrm{Créteil,} \mathrm{France;}{ }^{9} \mathrm{Hospital}$ Cochin, Paris, France; ${ }^{10}$ Bichat-Claude Bernard Hospital, Paris, France; ${ }^{11} \mathrm{CHU}$ de Reims, Hôpital Maison Blanche (Traumatologie-Orthopédie), Reims, France; ${ }^{12}$ Hospital Saint-Antoine Ap-Hp, Paris, France; ${ }^{13}$ Hospital Center Saint Philibert, Lille, France; ${ }^{14}$ Hospital Center De Roubaix, Roubaix, France; ${ }^{15}$ Clinical Anne D'artois, Béthune, France; ${ }^{16} \mathrm{Hospital}$ Center De Valenciennes, Valenciennes, France; ${ }^{17} \mathrm{CHRU}$ de Nancy - Hôpitaux de Brabois, Vand œuvre-lès-Nancy, France

Objectives: Secukinumab (SEC) is an interleukin-17 inhibitor used to treat patients with axial spondyloarthritis (axSpA) and psoriatic arthritis (PsA). Drug maintenance is often used as a proxy for treatment effectiveness and safety in real life settings. We aim to assess SEC maintenance in routine clinical practice and to identify survival predictors associated.

Methods: We conducted a retrospective, longitudinal, observational, multicenter study including all patients (pts) with axSpA or PsA who received at least 1 injection of SEC between July 2016 and October 2019. We collected patient's demographics and clinic characteristics, SEC date of initiation and dosage and dosage modification of SEC, previous biologic Disease-modifying antirheumatic drugs (bDMARDs) and concomitant treatments. Date and reasons of discontinuation - i.e., lack of efficacy, safety issue, sustained remission or others - were collected. Several potential maintenance predictors were tested: age, gender, disease (axSpA or PsA), smoking status, bDMARDs history and concomitant treatment. Among patients with non-radiographic axSpA (nr-axSpA), evidence of MRI sacroiliitis or elevated CRP were also assessed as potential maintenance predictors. Drug maintenance was analyzed by the Kaplan-Meier method and adjusted for baseline factors were estimated by log rank analysis.

Results: The main characteristics of the 561 pts included were the following: $363(64.7 \%)$ axSpA, 198 (35.3\%) PsA, 329 (58.6\%) female, mean age 45,6 +/- 12 years, $221(39.4 \%)$ smokers, 175 (31.2\%) radiographic sacroiliitis, 259 (46.2\%) MRI sacroiliitis, 198 (35.3\%) elevated CRP, 247 (44.0\%) HLA B27 positive, mean BASDAI $48,3+/-26.8 \%$. SEC was associated to methotrexate (MTX) in 139 pts $(24.8 \%)$ and was the first line bDMARD in 55 pts $(9.8 \%)$ The median drug maintenance (MDM) of SEC was 79 weeks (wk) [73-84]. At 52 wk, 245 pts $(60 \%)$ SpA were still treated with SEC. During the 3-year follow-up, 264 pts discontinued SEC: $180(68.2 \%)$ pts for lack of effectiveness, $47(17.8 \%)$ for adverse events, $14(5.3 \%)$ for others and $23(8.7 \%)$. SEC prescription as first line bDMARD was associated with longer survival versus second line or more: 111 wk [83-138] vs. 69 wk [57-80] ( $p=0.017$ ) (figure 1). MDM was not significantly different depending on gender, MTX combo, elevated CRP, axSpA vs PsA and smoking status. Among the nr-axSpA pts, MRI sacroiliitis or elevated CRP did not modify SEC maintenance $(p=0.68$ (figure 2).

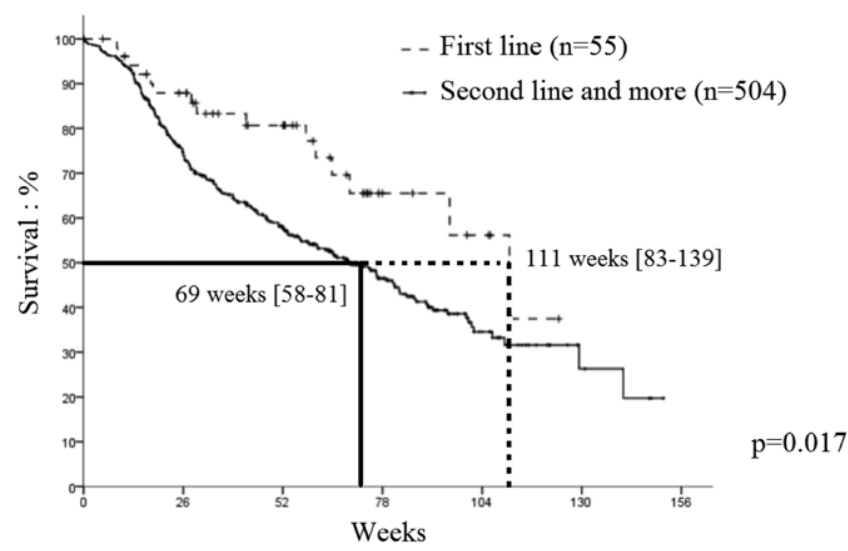

Figure 1. Secukinumab maintenance according to therapeutic line

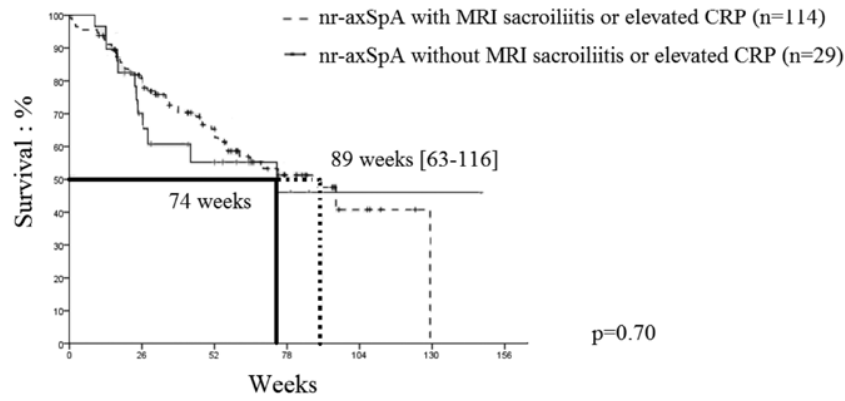

Figure 2. Secukinumab maintenance in nr-axSpA population

Conclusion: In routine clinical practice, SEC median maintenance was 79 weeks. Fist line administration was the only independent factor associated with improved SEC retention. Lack of effectiveness was the most common reason of discontinuation.

Disclosure of Interests: Benoît Flachaire: None declared, Jean-Guillaume Letarouilly Grant/research support from: Research grant from Pfizer, Céline Labadie: None declared, Nicolas Cohen Speakers bureau: Novartis, Janssen Vincent Pradel: None declared, Bruno Fautrel Grant/research support from: AbbVie, Lilly, MSD, Pfizer, Consultant of: AbbVie, Biogen, BMS, Boehringer 